\title{
Analysis of bond behaviour in strengthened reinforced concrete beam with carbon fiber reinforced polymer lamella
}

\author{
Milan Žmindák ${ }^{1, *}$, Pavol Novák ${ }^{1}$ and Vladimír Dekýśs ${ }^{1}$ \\ ${ }^{1}$ University of Žilina, Faculty of Mechanical Engineering, Department of Applied Mechanics, \\ Univerzitná 1, 01026 Žilina, Slovakia
}

\begin{abstract}
Carbon fiber reinforced polymer (CFRP) can be used to strengthen the reinforced concrete (RC) beams. The debonding is the main failure model and strengthening is limited. The paper deals with the finite element analysis of influence of CFRP strip on stress distribution in a steel reinforced concrete beam loaded by four-point bending on RC beam with and without CFRP lamella. Simulation of the delamination is modelled by a cohesion zone material model using ABAQUS and ANSYS software.
\end{abstract}

\section{Introduction}

In the past decades, the use of composites for strengthening and repairing concrete structures has gained significant importance in civil engineering [1-3]. There are a large number of new, innovative building materials on the market. In order to avoid a drastic impact of building materials now or in the future, these materials as well as their manufacture and use must comply with the ecological standards. The trend of developing new building materials is not characterised by inventing something new, but rather by improving something long-existing. The aim of this paper is to create a model to simulate a four-point bending loading experiment on a reinforced concrete beam with and without carbon-fibre reinforced polymer.

\section{FEM simulation}

Experimental measurements of four-point bending of a reinforced concrete beam were carried out in our laboratory. Fig. 1 shows that the contact between the load and the beam, as well as the contact between the supports and the beam. The surface representing half profile of the T-beam is divided into smaller areas, borderlines of which will be used later to create a mesh of link/beam elements forming the steel reinforcement. The element Solid65 was used for discretization the steel reinforcement. The dimensions of the full-size beams are $3600 \mathrm{~mm} \times 350 \mathrm{~mm} \times 400 \mathrm{~mm}$ and the span between the supports was $3310 \mathrm{~mm}$. Moreover, the lower part of the beam includes a milled groove in the covering layer. The groove is $4 \mathrm{~mm}$ wide, $20 \mathrm{~mm}$ deep, and $3000 \mathrm{~mm}$ long, positioned symmetrically in relation to the transverse plane of the beam symmetry (Fig. 2).

${ }^{*}$ Corresponding author: milan.zmindak@,fstroj.uniza.sk 


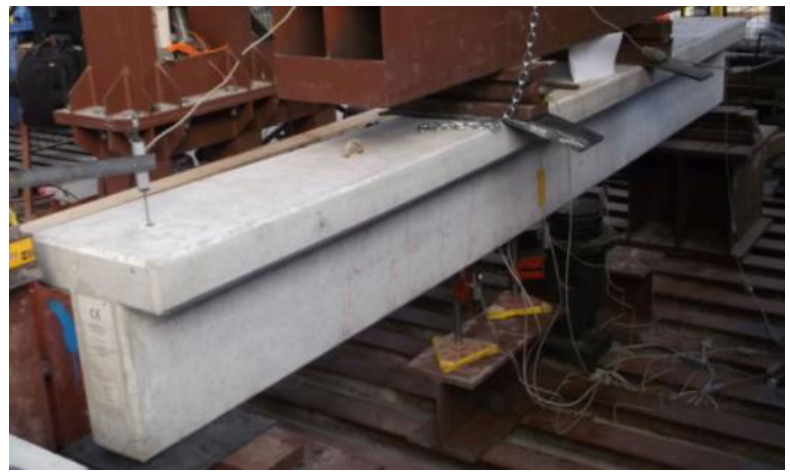

Fig. 1. Experimental stand for four-point bending test.

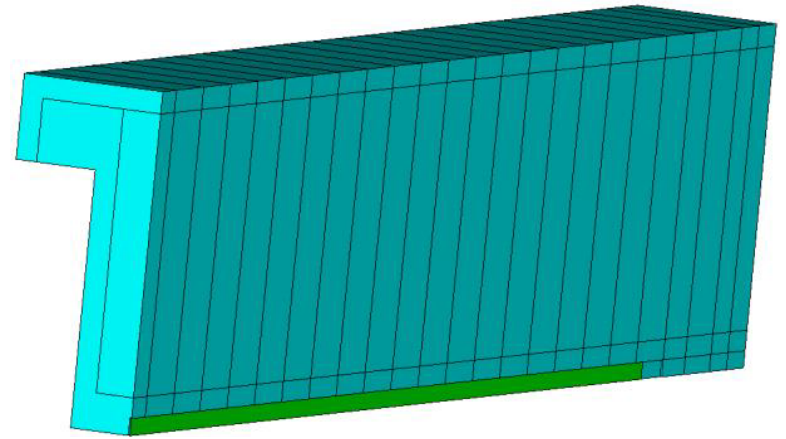

Fig. 2. Geometric model of the reinforced concrete beam with a gap or the composite lamella.

Bonding of the lamella with the concrete is modelled using the conta173 contact elements, considering the contact with adhesive bonding (bonded always contact), and using a cohesive material model (CZM - Cohesive Zone Material). We used the data provided by the manufacturer of the glue. We assumed a dominant shear mode of breaking the bonded joint. This material model requires entering $\tau_{\max }=12 \mathrm{MPa}$ (maximum equivalent contact shear stress), $\delta_{t}=1 \mathrm{~mm}$ (tangential displacement after debonding). This value is not stated by the manufacturer and must be obtained through an experiment [4].

In the post-processing, for the contact defined in the above manner, we can evaluate the generally known data, such as contact status, contact gap, contact pressure, as well as the following variables: DPARAM - debonding parameter - this parameter takes a value from 0 to 1 , where the value 1 corresponds with the breaking of the bonded joint, and the value 0 corresponds with the initial unbroken joint, DTSTARI - the time step at which debonding occurred.

\subsection{Boundary conditions}

The solution is significantly influenced also by the manner used for the beam positioning modelling. In order to prevent the formation of stress concentrators, we modelled a plane support with a width corresponding to the experiment, and a joint in the support width centre. The above was done using shell elements - shell181. The nodes in the support width centre were removed of all degrees of freedom for displacement, and we retained all 
degrees of freedom for rotation. Contact with the beam was done using the conta173 and target 170 contact elements. A support modelled in this manner has no longer caused the formation of stress concentrators in its vicinity; therefore no cracks occurred in this area $[5,6]$.

The load acting on the beam in its upper part was created as a quarter of the total force $F=110 \mathrm{kN}$ acting on the small area formed by the experiment requirements. The small area is $150 \mathrm{~mm}$ wide and its distance from the beam centre is $500 \mathrm{~mm}$ [7].

\subsection{Material properties}

RC structures strengthened by FRP are based on combination of concrete, steel and FRP. This section summarizes the material properties of all components:

Concrete: the concrete class C35/45-C10, 04-D $\max 16-\mathrm{S} 3$ according to STN EN 206-1 was used. It properties are: Young's modulus $E=34 \mathrm{GPa}$, ductility stated by the manufacturer $\varepsilon_{c u}=0.035$, Poisson's rate $\mu=0.2$, the concrete density $\rho=2400 \mathrm{~kg} \cdot \mathrm{m}^{-3}$.

Steel reinforcement: the reinforcing steel B500 B according to STN EN 10027 was used: ultimate tensile strength $f_{y}=500 \mathrm{MPa}$, ultimate tensile strength $f_{t}=550 \mathrm{MPa}$, Young's modulus $E=200 \mathrm{GPa}$, ductility $\varepsilon=0.005$, Poisson's ratio $\mu=0.3$.

Composite lamella: the simulated composite lamella is made by the BASF company. Its trade name is MBRACE CFK 150/2 000. The composite lamella dimensions are $20 \times 1.4 \times 3000 \mathrm{~mm}$. For this lamella type, the manufacturer states the Young's modulus larger than $165 \mathrm{GPa}$, Poisson's number $\mu=0.2$ and the recommended design tensile load is $51.8 \mathrm{kN}$, which means that the uniaxial tension stress is $1850 \mathrm{MPa}$ at the lamella crosssection of $28 \mathrm{~mm}^{2}$.

High-strength epoxy glue: to affix the lamella into the groove in the beam it was used high-strength epoxy adhesive with a high glass transition temperature for the MBRACE lamella system by BASF, with the trade name MBRACE Laminate Adhesive HT. Its bond strength is $>14 \mathrm{MPa}$, compressive strength is $73 \mathrm{MPa}$, bending elastic modulus is 4263 $\mathrm{MPa}$, glass transition temperature is $\geq 40^{\circ}$, shrinkage/ expansion is $\leq 0.1 \%$ [5].

\section{FEM solution}

In the calculation we considered the geometric linearity of the task because the achieved bending is sufficiently small against the beam dimensions. We spread the calculation over several loading states. We did so, among other things, also due to a good convergence of the beam contact with the lower articulated support. Another reason was the concrete deterioration at higher loading values, and it was appropriate to reduce the loading increments for a faster task solving. The concrete failure model caused that it was impossible to work with standard values for the convergence criteria (these were too strict). The value of force imbalance, which was considered as the convergence criterion, was set to $200 \mathrm{~N}$.

\section{Analysis of results}

Comparisons of the load-tensile displacement plots from the FE analyses with the experimental data for the reinforced concrete beam at midspan are shown in Fig. 3. This figure shows that the displacements from FE analyses correlate well with those from experimental data in the range loading force 0 to $40 \mathrm{kN}$. Higher displacement value in the experimental beam is possibly due to a local effect caused by the major cracks, which take place close to the midspan. Fig. 4 shows the maximum deflection in the middle of the 
reinforced concrete beam with lamella, and it reaches the value $w_{\max }=7.57 \mathrm{~mm}$. This value is slightly reduced compared with the model with CFRP lamella [8]. Due to bending, the free end of the beam behind the support is displaced upwards by $0.89 \mathrm{~mm}$. Fig. 5 shows the first principal stress in the concrete. This value indicates the sites that are critical for the concrete failure due to a high tensile stress, which concrete naturally "does not like". High values are present in the beam lower side. The maximum is reached due to concrete failure consideration, and it appears near the steel reinforcement.

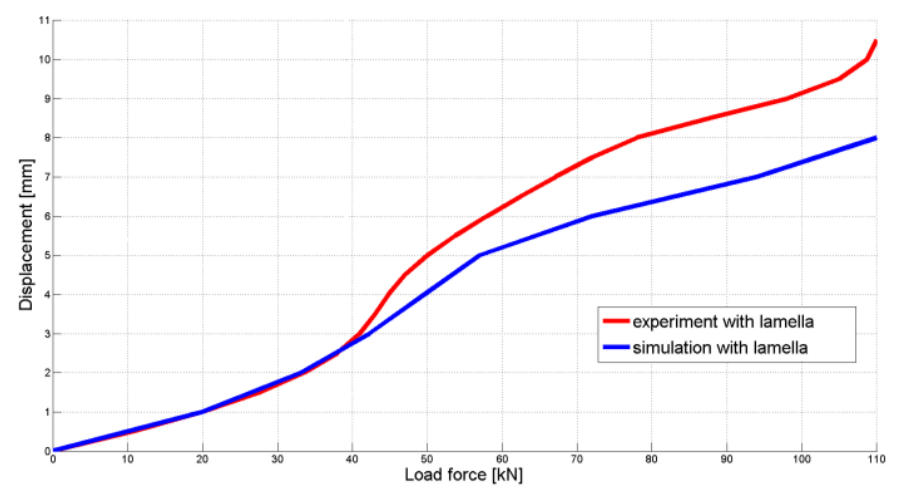

Fig. 3. The plot of displacement versus loading force.
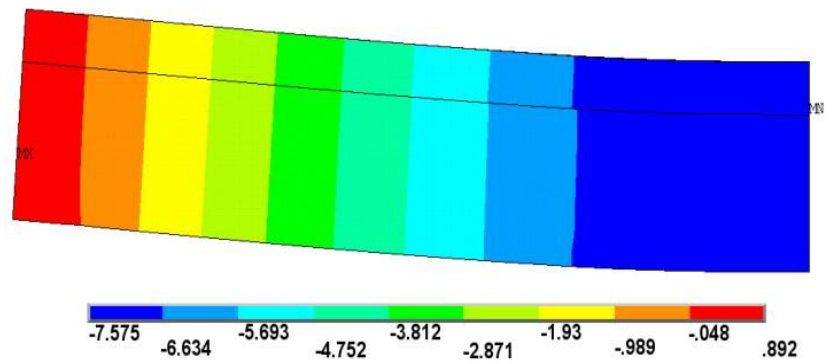

Fig. 4. Displacement of the reinforced concrete beam with a lamella.

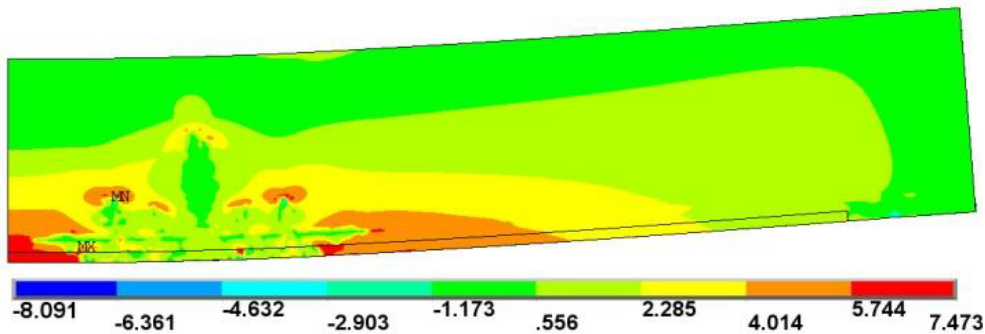

Fig. 5. First principal stress in the concrete.

Due to the lamella groove, and the lamella with a high elasticity modulus, concentration of stresses occurs near the original beam/groove interface. The maximum value dropped and moved to this area from the steel reinforcement site. 
Fig. 5 shows the third principal stress in the concrete. This value shows the areas where concrete crushing might occur in case of exceeding the concrete compressive strength. The maximum reached value is $-28.1 \mathrm{MPa}$ is below the used concrete compressive strength, therefore there should be no crushing. The stress value was higher compared to the previous case and, like in the first principal stress, the value moved from the steel reinforcement to the site of the lamella groove [8].

The course of axial stresses in the reinforcement is shown in Fig. 7. As we can see, compressive stress occurs in the upper part of the reinforcement. The maximum compressive stress emerged near the action of the loading pressure, and the compressive stress value in the reinforcement reached the value $p_{\text {max,steel }}=164.32 \mathrm{MPa}$. The maximum tensile stress emerged in the bottom part of the steel reinforcement, at the site under the loading force, and its value reached $\sigma_{\text {tmax,steel }}=424.63 \mathrm{MPa}$. This value is lowered compared with the model without the composite reinforcement, but it is still near the value of the yield strength $R_{c}$.

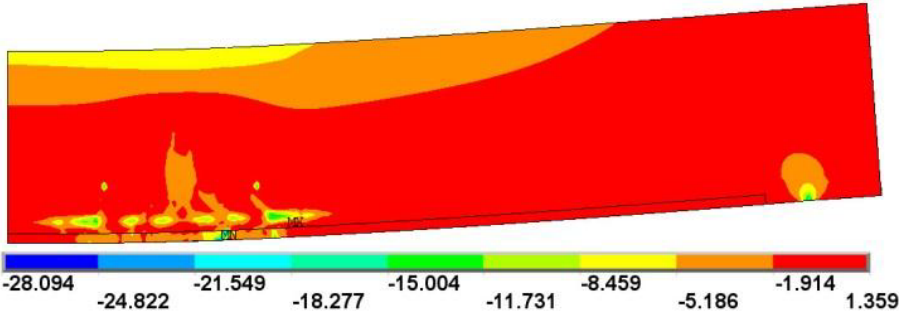

Fig. 6. Third principal stress in the concrete.

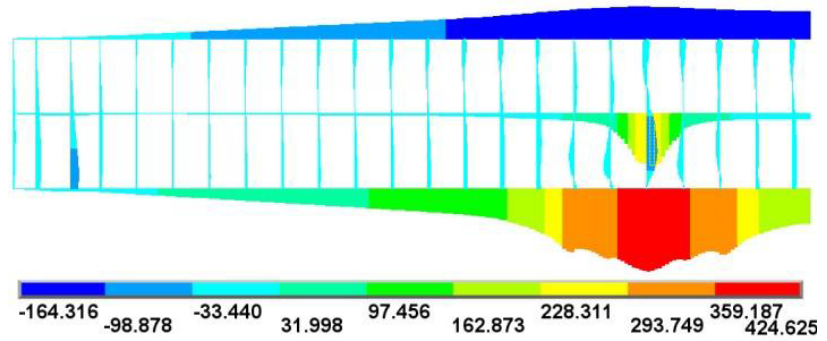

Fig. 7. Axial stresses in the reinforcement.

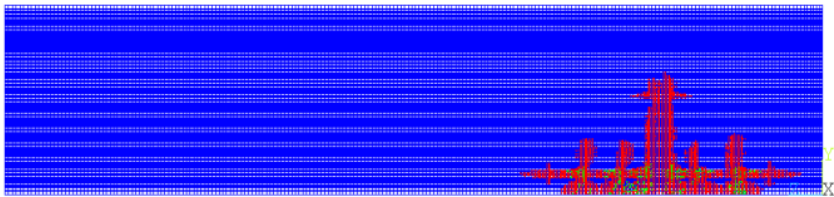

Fig. 8. Depiction of cracks in the concrete.

Fig. 8 shows the pink-coloured cracks formed in the concrete as a result of exceeding the concrete tensile strength. These cracks occur around the T-shaped steel stirrups. 

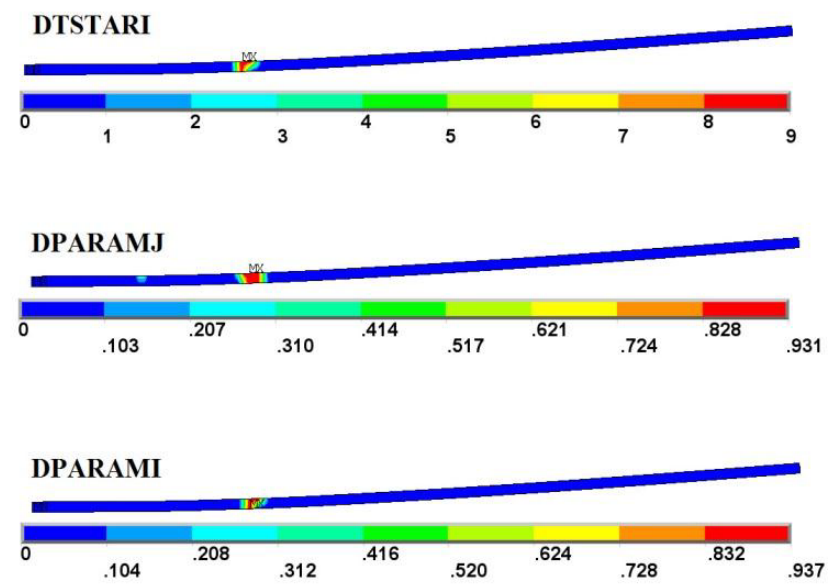

Fig. 9. The probability of adhesion loss with loading steps.

The shape and length of cracks has changed significantly compared with the case without a lamella. Although there is still one significantly long crack at the site under the acting load, other cracks are of approximately the same length

From Fig. 9 we can see that the DPARAMJ and DPARAMI values indicates the probability of adhesion loss of the glue and the lamella. The maximum value is approximately 0.94 , which represents a $94 \%$ probability of adhesion loss. According to the DTSTARI value, this should occur in the last, $9^{\text {th }}$ loading step, at the site filled with red.

\section{Conclusions}

The results obtained show that the use of the above-mentioned composite lamella changes the stress distribution in the concrete matrix as well as in the steel reinforcement. This is manifested by the reduction in the maximum stress values in the tensile domain for both the concrete and the reinforcement, and in case of the concrete also by increased maximum compression stresses, which is favourable for concrete. The maximum bending (deflection) values are very similar in the two cases. It also results from the data obtained that there will be no adhesion compromise between the concrete and the lamella (the maximum value is $94 \%$ of the bond ultimate shear strength), but there will occur delamination in the concrete. The shape and size of the cracks in the concrete have changed as well.

The authors gratefully acknowledge for support the Slovak and Technology Assistance Agency register under number APVV-0736-12 and Slovak Grant Agency VEGA 1/0983/15.

\section{References}

1. E. J. Barbero, Finite Element Analysis of Composite Materials Using ANSYS (CRC Press 2014)

2. L. Dahmani, A. Khennane, S. Kaci, Strength Mat. 42 (2010)

3. M. Halapi, Z. Murcinkova, In: Int. Conf. on Manufacturing Engineering and Materials, (2016) 
4. M. Zmindak, P. Novak, V. Dekys, Advanced Materials Research 897 (2014)

5. E. Kormanikova, K. Kotrasova, Dynamic of Civil Engineering and Transport Structures and Wind Engineering, Book Series: Applied Mechanics and Materials 617, (2014)

6. E. Kormanikova, K. Kotrasova, Key Eng. Mat. 635, 85-88 (2015)

7. A. Cavojcova, M. Moravcik, F. Bahleda, J. Jost, Procedia Engng. 92 (2014)

8. M. Žmindák, P. Novák, P. Pastorek, Proceedings of Mechanics of Composite Materials and Structures, Sušice (2016) 